\title{
Application of Problem Based Learning (PBL) Learning Model To Increase Science Learning Outcomes
}

\section{Wulan Eka Febrianti}

SD Negeri Malahayu 03 Brebes wulaneka020@gmail.com

\section{Article History}

received 3/12/2020

\begin{abstract}
This study purpose to improve learning outcomes in Science about the solar system in grade IV students of SDN Malahayu 03 Banjarharjo, District, 2019/2020 academic year. This study uses a Classroom Action Research (CAR) model which is carried out in 2 cycles. The results showed that there was an increase in student learning outcomes using the Problem Based Learning $(P B L)$ learning model. In the pre-cycle stage of 22 students who achieved learning completeness 5 students (23\%). Then in the first cycle of learning completeness reached 13 students (59\%) and in the second cycle there was an increase to 20 students (91\%). So the conclusion of this study shows that learning with the the Problem Based Learning (PBL) learning model improves science learning outcomes about the solar system in grade IV students of SDN Malahayu 03, Banjarharjo District, semester I of the 2019/2020 school year.
\end{abstract}

Keywords: problem based learning, learning outcomes, science

\section{Abstrak}

Penelitian ini bertujuan untuk meningkatkan hasil belajar pada siswa kelas IV SD Negeri Malahayu 03 Kecamatan Banjarharjo Kabupaten Brebes Tahun Pelajaran 2019/2020. Penelitian ini menggunakan model Penelitian Tindakan Kelas (PTK) yang dilaksanakan dalam 2 siklus. Hasil penelitian menunjukkan bahwa terdapat peningkatan hasil belajar siswa dengan menggunakan model pembelajaran Problem Based Learning (PBL). Pada tahap pra siklus dari 22 siswa yang mencapai ketuntasan belajar 5 siswa (23\%). Kemudian pada siklus 1 ketuntasan belajar mencapai 13 siswa (59\%) dan pada siklus 2 terjadi peningkatan menjadi 20 siswa $(91 \%)$. Sehingga kesimpulan penelitian ini menunjukkan bahwa pembelajaran dengan model pembelajaran Problem Based Learning (PBL) dapat meningkatkan hasil belajar IPA siswa kelas IV SDN malahayu 03 Kecamatan Banjarharjo semester I tahun ajaran 2019/2020.

Kata kunci: problem based learning, hasil belajar, IPA

Social, Humanities, and Education Studies (SHEs): Conference Series https://jurnal.uns.ac.id/shes

p-ISSN 2620-9284

e-ISSN 2620-9292 


\section{PENDAHULUAN}

Pendidikan sangat diperlukan oleh manusia sebagai sarana untuk pengembangan diri, karena pendidikan merupakan salah satu fondasi yang menentukan ketangguhan dan kemajuan suatu bangsa. Pendidikan dapat diperoleh melalui jalur formal dan jalur informal. Sekolah sebagai Pendidikan formal dituntut memberikan pembelajaran yang bermakna. Sebagaimana tertuang dalam UndangUndang Republik Indonesia No. 20 Tahun 2003 pasal 1 ayat 1 tentang Sistem Pendidikan Nasional yang berbunyi "Pendidikan adalah usaha sadar dan terencana untuk mewujudkan suasana belajar dan proses pembelajaran agar siswa secara aktif mengembangkan potensi dirinya untuk memiliki kekuatan spirutual keagamaan, pengenalan diri, kepribadian, kecerdasan, akhlak mulia, serta keterampilan yang diperlukan dirinya, masyarakat bangsa dan negara".

Miarso dalam Rusmono (2012: 6) mengemukakan bahwa pembelajaran adalah suatu usaha yang disengaja, bertujuan, dan terkendali agar orang lain belajar atau terjadi perubahan yang relatif menetap pada diri orang lain. Dalam proses pembelajaran terdapat peran siswa sebagai subyek belajar. Aktifitas siswa dalam pembelajaran tidak hanya mendengarkan penjelasan guru kemudian mencatat materi yang disampaikan guru ,karena saat ini guru bukan lagi satu-satunya sumber informasi bagi siswa. Lebih dari itu siswa diharapkan mampu berpartisipasi aktif dalam pembelajaran. Guru sebagai fasilitator harus mampu menciptakan lingkungan belajar yang menyenangkan bagi siswa sehingga siswa semangat mengikuti pembelajaran dan siswa mendapatkan pembelajaran yang bermakna. Melalui pembelajaran yang aktif, siswa dapat memperoleh pengalaman belajar yang nyata dan bermakna.

Mata pelajaran IImu Pengetahuan Alam (IPA) adalah salah satu mata pelajaran pokok dalam kurikulum pendidikan di Indonesia, IPA selalu ada dalam pembelajaran dari jenjang Sekolah Dasar (SD) hingga Perguruan Tinggi. IPA sendiri merupakan "rumpun ilmu yang memiliki karakteristik khusus yang mempelajari fenomena alam yang faktual, baik berupa kenyataan atau kejadian dan hubungan sebab-akibatnya" (Wisudawati dan Sulistyowati, 2014, hlm. 22). IImu Pengetahuan Alam (IPA) merupakan salah satu disiplin ilmu yang didalamnya mengkaji berbagai kajian ilmu alam. Mata pelajaran IPA ini sangat penting kedudukannya dalam masyarakat karena erat kaitannya dengan kehidupan sehari- hari.

Namun selama ini masih banyak siswa yang mengalami kesulitan dalam memahami dan mengikuti pelajaran ini. Tidak sedikit dari mereka beranggapan bahwa mata pelajaran IPA itu membosankan dikarenakan terlalu banyak cakupan materi yang harus mereka pelajari. Guru masih menggunakan metode dan model pembelajaran konvensional sehingga siswa merasa bosan dan pasif dalam pembelajaran. Hal ini berpengaruh terhadap hasil belajar siswa.

Hasil observasi yang dilakukan pada pembelajaran IPA pada materi gaya di SDN Malahayu 03 yang berlokasi di Kecamatan Banjarharjo, Kabupaten Brebes pada siswa kelas IV menunjukan bahwa sebagian besar peserta didik terlihat pasif dan belum memiliki kemampuan berpikir kritis. Sebagian besar peserta didik belum dapat mengemukakan pendapatnya sendiri untuk proses penyelesaian masalah yang terjadi dalam pembelajaran IPA, sebagia besar siswa masih malu bertanya ketika belum memahami materi sehingga berpengaruh terhadap hasil belajar siswa pada mata pelajaran IPA. Untuk mencapai tujuan yang diharapkan peneliti menggunakan model Problem Based Learning (PBL) untuk meningkatkan hasil belajar siswa pada mata pelajaran IPA. 
Menurut Sani (2015, hlm. 127) Problem Based Learning (PBL) merupakan pembelajaran yang penyampainnya dilakukan dengan cara menyajikan suatu permasalahan, mengajukan pertanyaan- pertanyaan, memfasilitasi penyelidikan, dan membuka dialog. Ditegaskan kembali oleh Tung (2015, hlm. 228) bahwa "pembelajaran ini melibatkan murid untuk memecahkan masalah melalui tahap-tahap metode ilmiah sehingga mereka dapat memelajari pengetahuan yang berhubungan dengan masalah tersebut dan sekaligus memiliki keterampilan untuk memecahkan masalah. Dalam model pembelajaran PBL masalah yang disuguhkan yaitu masalah nyata dalam kehidupan sehari-hari dan perlu banyak informasi yang relevan dan sesuai untuk menemukan proses pemecahan masalah dalam pembelajaran. Model Problem Based Learning (PBL) memiliki 5 sintak diantaranya orientasi siswa pada masalah, mengorganisasikan siswa untuk belajar, membimbing penyelidikan individual atau kelompok, mengembangkan dan menyajikan hasil hasil karya, menganalisis dan mengevaluasi proses pemecahan masalah. (Suprijono, $2009 \mathrm{hlm}$. 74). Peneliti tertarik untuk menerapkan model Problem Based Learning (PBL) karena sesuai dengan latar belakang permasalahan yang ditemukan pada siswa kelas IV SDN Malahayu 03 ketika pembelajaran IPA berdasarkan hasil observasi pra siklus.

\section{METODE}

Penelitian ini merupakan Penelitian Tindakan kelas (PTK). Peneliti melaksanakan Penelitian Tindakan Kelas (PTK) pada siswa kelas IV SDN Malahayu 03 Kec.Banjarharjo, Kab. Brebes 2019/2020. Peneliti menggunakan desain Model Kemmis dan Mc. Taggart yang memiliki 4 tahap .Tahapanya yaitu: planning, acting, observing, dan reflecting. (Wiriaatmadja, 2005, hlm. 66). Partisipan dalam penelitian ini adalah peserta didik kelas IV SDN Malahayu 03 yang terdiri dari 22 peserta didik dengan peserta didik laki-laki berjumlah 8 orang dan perempuan berjumlah 14 orang.

Sebelum melaksanakan Penelitian Tindakan kelas ( PTK) dengan menerapkan model pembelajaran Problem Based Learning (PBL), terlebih dulu peneliti melakukan observasi awal pra siklus. Pra siklus dilaksanakan pada tanggal 4 November 2019. Berdasarkan hasil temuan yang ditemukan dari data hasil observasi awal pra siklus yang berupa hasil observasi aktivitas siswa dan guru serta hasil belajar IPA, peneliti melaksanakan penelitian dengan menerapkan Problem Based Learning (PBL) dalam dua siklus. Siklus 1 dilaksanakan pada tanggal 12 November 2019 dan siklus 2 dilaksanakan pada tanggal 26 November 2019. Instrumen yang digunakan yaitu lembar observasi aktivitas guru dan siswa dan soal tes evaluasi. Teknik pengumpulan data yang digunakan yaitu Teknik tes dan non tes. Teknik analisis data yang digunakan adalah deskriptif kualitatif dan kuantitatif.

\section{HASIL DAN PEMBAHASAN}

Penelitian ini menggunakan desain penelitian tindakan kelas. Penelitian tindakan kelas adalah cara suatu kelompok atau seseorang dalam mengorganisasikan suatu kondisi sehingga mereka dapat mempelajari pengalaman mereka dan membuat pengalamannya dapat diakses oleh guru lain. (Hatimah, $2007 \mathrm{hlm}$. 83). Desain penelitian yang digunakan dari Model Kemmis dan Mc. Taggart yang memiliki 4 tahap .Tahapanya yaitu: planning, acting, observing, dan reflecting. (Wiriaatmadja, 2005, hlm. 66). Tiap-tiap siklus terdapat empat tahap. Tahap perencanaan berupa kegiatan menyusun rancangan penelitian yaitu mempersiapkan rancangan pembelajaran, lembar observasi aktivitas guru dan siswa dan lembar evaluasi. Tahap Tindakan yaitu realisasi tindakan peneliti berdasarkan perencanaan yang telah disusun. Tahap ketiga adalah pengamatan, tahap ini dilakukan oleh peneliti sebagai pengajar di kelas dan teman sejawat. Tahap keempat adalah refleksi dimana peneliti melihat dan mempertimbangkan hasil tindakan yang dilakukan. 
Sebelum melaksanakan Penelitian Tindakan kelas ( PTK), terlebih dulu peneliti melakukan observasi awal melakukan pra siklus untuk mengidentifikasi permasalahan - permasalahan yang ada pada saat berlangsungnya proses pembelajaran di kelas IV SDN Malahayu 03. Observasi dilaksanakan dengan memperhatikan guru mengajar, keaktifan siswa dan hasil belajar mata pelajaran IPA. Pra siklus dilaksanakan pada tanggal 4 November 2019. Berdasarkan hasil temuan yang ditemukan dari observasi awal pra siklus yang berupa hasil observasi aktivitas siswa dan guru serta hasil belajar mata pelajaran IPA, peneliti melaksanakan penelitian dengan menerapkan Problem Based Learning (PBL) dalam dua siklus. Siklus 1 dilaksanakan pada tanggal 12 November 2019 dan siklus 2 dilaksanakan pada tanggal 26 November 2019.

Data hasil belajar siswa pra siklus, siklus 1 dan siklus 2 yang dilakukan peneliti dapat dilihat pada tabel di bawah ini :

Tabel 1. Perbandingan Hasil Belajar Siswa pada Prasiklus, Siklus I dan Siklus II

\begin{tabular}{|c|c|c|c|c|c|c|c|}
\hline \multirow{2}{*}{ Nilai } & \multirow{2}{*}{ Keterangan } & \multicolumn{2}{|c|}{ Prasiklus } & \multicolumn{2}{|c|}{ Siklus I } & \multicolumn{2}{|c|}{ Siklus II } \\
\hline & & $\mathbf{F}$ & $\mathbf{P}(\%)$ & $\mathbf{F}$ & $\mathbf{P}(\%)$ & $\mathbf{F}$ & $\mathbf{P}(\%)$ \\
\hline$\geq 70$ & Tuntas & 5 & 23 & 13 & 59 & 20 & 91 \\
\hline \multirow[t]{5}{*}{$<70$} & Tidak Tuntas & 17 & 77 & 9 & 41 & 2 & 9 \\
\hline & Jumlah & 22 & 100 & 22 & 100 & 22 & 100 \\
\hline & Rata-rata & \multicolumn{2}{|c|}{50} & \multicolumn{2}{|c|}{75} & \multicolumn{2}{|r|}{85} \\
\hline & Minimum & \multicolumn{2}{|c|}{40} & \multicolumn{2}{|c|}{70} & \multicolumn{2}{|r|}{70} \\
\hline & Maksimum & \multicolumn{2}{|c|}{70} & \multicolumn{2}{|c|}{90} & \multicolumn{2}{|r|}{100} \\
\hline
\end{tabular}

Keterangan :

$$
\begin{aligned}
& \mathrm{F}=\text { Frekuensi } \\
& \mathrm{P}=\text { Persentase }
\end{aligned}
$$

\section{Pra Siklus}

Berdasarkan tabel 1 terlihat bahwa hasil belajar siswa pada tahap pra siklus yang ditinjau dari ketuntasan belajar, nilai minimum, nilai maksimum dan nilai rata- rata dari pra siklus pada pembelajaran IPA siswa yang tuntas dan memenuhi KKM berjumlah 5 siswa dengan presentase 23\% dan siswa yang belum tuntas berjumlah 17 siswa dengan presentase $77 \%$. Berdasarkan data hasil belajar siswa mata pelajaran IPA pada pra siklus yang menunjukkan belum memenuhi ketuntasan klasikal, peneliti menerapkan Problem Based Learning (PBL) dalam pembelajaran IPA. Peneliti merancang perangkat pembelajaran pada KD 3.3 Memahami hubungan antara gaya, gerak dan energi melalui pengamatan, serta mendeskripsikan penerapannya dalam kehidupan sehari-hari kemudian membuat lembar observasi aktivitas guru dan siswa serta soal tes evaluasi siswa.

2. Siklus 1

Siklus 1 dilaksankan pada tanggal 12 November 2019. Peneliti menerapkan model pembelajaran Problem Based Learning (PBL) pada pembelajaran IPA KD 3.3 Memahami hubungan antara gaya, gerak dan energi melalui pengamatan, serta mendeskripsikan penerapannya dalam kehidupan sehari-hari. Pembelajaran dengan menggunakan model pembelajaran Problem Based Learning ( $P B L$ ) dilakukan sesuai sintak yaitu orientasi siswa terhadap masalah, mengorganisasi siswa untuk belajar, membimbing penyelidikan individual dan kelompok, 
mengembangkan dan menyajikan hasil karya, menganalisis dan mengevaluasi proses pemecahan masalah.

Berdasarkan tabel 1, dapat dilihat bahwa hasil belajar siswa pada pembelajaran IPA mengalami peningkatan dari pra siklus. Pada siklus 1 siswa yang tuntas dan memenuhi KKM berjumlah 13 siswa dengan presentase 59\% dan siswa yang belum tuntas berjumlah 9 siswa dengan presentase $41 \%$. Berdasarkan hasil refleksi siklus 2 memutuskan untuk melanjutkan pke siklus 2 karena belum memenuhi ketuntasan klasikal yang diharapkan.

3. Siklus 2

Siklus 2 dilaksankan pada tanggal 26 November 2019. Peneliti menerapkan model pembelajaran Problem Based Learning (PBL) pada pembelajaran IPA KD 4.3 Memahami hubungan antara gaya, gerak dan energi melalui pengamatan sesuai dengan menerapkan model pembelajaran Problem Based Learning (PBL).

Pembelajaran dilakukan sesuai sintak PBL yaitu orientasi siswa terhadap masalah, mengorganisasi siswa untuk belajar, membimbing penyelidikan individual dan kelompok, mengembangkan dan menyajikan hasil karya, menganalisis dan mengevaluasi proses pemecahan masalah.

Berdasarkan tabel 1, dapat dilihat bahwa hasil belajar siswa pada pembelajaran IPA mengalami peningkatan dari siklus 1. Pada siklus 2 siswa yang tuntas dan memenuhi KKM berjumlah 20 siswa dengan presentase $91 \%$ dan siswa yang belum tuntas berjumlah 2 siswa dengan presentase $9 \%$.

Hasil belajar siswa pada pra siklus, siklus 1 dan siklus 2 selalu mengalami peningkatan dan pada siklus 2 sudah memenuhi ketuntasan klasikal yang diharapkan. Peningkatan presentase ketuntasan hasil belajar siswa dapat dilihat pada gambar 1

Data Hasil Belajar Siswa

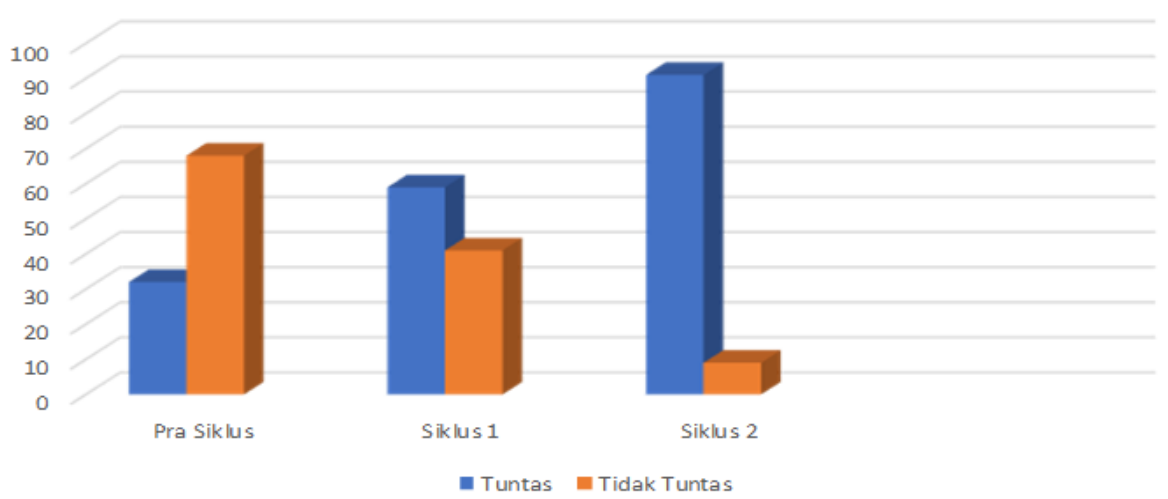

Gambar 1. Perbandingan Hasil Belajar Siswa pada Prasiklus, Siklus I dan Siklus II

Berdasarkan gambar 1, terlihat bahwa Pembelajaran menggunakan model pembelajaran Problem Based Learning (PBL) berhasil meningkatkan hasil belajar IPA kelas IV SD Negeri Malahayu 03 Kec.Banjarharjo, Kab. Brebes semester I tahun pelajaran 2019/2020, terlihat hasil belajar IPA siswa kelas IV SDN Malahayu 03 selalu mengalami peningkatan pada setiap siklus dan pada akhir siklus 20 siswa sudah mencapai KKM dengan presentase $91 \%$ dan hanya 2 siswa yang tidak memenuhi KKM dengan presentase 9\%. Ini menunjukkan bahwa sudah memenuhi ketuntasan klasikal yang diharapkan. Hal ini sejalan dengan penelitian yang dilakukan oleh Riana Rahmasari, 2016 dengan judul " Penerapan Model Problem Based Learning untuk Meningkatkan Hasil Belajar IPA pada Siswa Kelas IV SD Negeri Nglempong Sleman 
Yogyakarta", menunjukkan bahwa penggunaan model pembelajaran Problem Based Learning (PBL) dapat meningkatkan hasil belajar siswa. Pada kondisi awal prasiklus, perolehan hasil belajar siswa kelas IV SD Negeri Nglempong Ngaglik Sleman dalam mata pelajaran IPA, sebanyak 14 siswa atau 58,33\% telah memenuhi KKM yang telah ditetapkan oleh sekolah yaitu 65 . Sedangkan sebanyak 10 orang atau $41,67 \%$ belum memenuhi KKM. Dengan demikian dapat disimpulkan bahwa skal prasiklus hasil belajar IPA siswa kelas IV SD Negeri Nglempong Ngaglik Sleman tergolong rendah. Setelah diberikan tindakan dengan model pembelajaran Problem Based Learning (PBL) pada mata pelajaran IPA, terdapat peningkatan nilai rata- rata 78,58. Sebanyak 23 siswa atau $95,83 \%$ memenuhi KKM dan hanya 1 siswa atau $4,17 \%$ yang tidak memenuhi KKM.

\section{SIMPULAN}

Berdasarkan hasil penelitian dan pembahasan, dapat disimpulkan bahwa peningkatan hasil belajar IPA pada siswa kelas IV SD Negeri Malahayu $03 \mathrm{Kec}$. Banjarharjo Kab. Brebes dapat diupayakan melalui pembelajaran dengan model pembelajaran Problem Based Learning (PBL). Hal ini terlihat pada hasil observasi aktivitas guru dan siswa yang mengalami peningkatan setelah menerapkan model pembelajaran Problem Based Learning (PBL).

Kemudian berdasarkan analisis dan simpulan yang sudah dipaparkan oleh peneiti, maka peneliti memberikan beberapa saran bagi guru agar lebih kreatif dalam memilih strategi, metode atau model pembelajaran agar pembelajaran lebih inovatif dan bermakna. Salah satunya adalah dengan menerapkan model pembelajaran Problem Based Learning (PBL) agar pembelajaran lebih menarik dan dapat meingkatkan hasil belajar siswa.

\section{DAFTAR PUSTAKA}

Afriki. 2013. Buku Tematik Terpadu Tema 2 Selalu Berhemat Energi. Jakarta: Kementerian Pendidikan dan Kebudayaan.

Departemen Pendidikan Nasional. UU RI Nomor 20 Tahun 2003, Tentang Sistem Pendidikan Nasional Tahun 2003. Bandung: Citra Umbara.

Djojosoediro, Wasih. Hakikat IPA dan Pembelajaran IPA SD, Pdf. Diakses pada tanggal 20 Februari 2020.

Hatimah, at. All. 2007. Penelitian Pendidikan. Bandung: UPI Press

Khoe, Yao Tung. 2015. Pembelajaran dan Perkembangan Belajar. Jakarta : Indeks.

Rahmasari, Riana. 2016. Penerapan Model Pembelajaran Problem Based Learning Untuk Meningkatkan Hasil Belajar IPA Pada Siswa Kelas IV SD Negeri Nglempong Sleman Yogyakarta. Skripsi. Fakultas Keguruan dan IImu Pendidikan Universitas Negeri Yogyakarta: Yogyakarta.

Rusman. 2016. Pembelajaran Tematik Terpadu: Teori, Praktik dan Penilaian. Jakarta: Rajawali Pers.

Sani, Ridwan Abdullah. 2015. Pembelajaran Saintifik Untuk Implementasi Kurikulum 2013. Jakarta: Bumi Aksara.

Sulistiyanto, Heri \& Wiyono, Edy. 2008. Ilmu Pengetahuan Alam untuk SD/MI Kelas IV. Jakarta: Pusat Perbukuan

Suprijino, Agus. 2009, Cooperative Learning, Teori dan Aplikasi PAIKEM. Yogjakarta: Pustaka Pelajar.

Wisudawati, Widi dan Sulistiyowati, Eka. 2017. Metodologi Pembelajaran IPA. Jakarta:

Bumi Aksara. 